University of Texas Rio Grande Valley

ScholarWorks @ UTRGV

Chemistry Faculty Publications and

Presentations

College of Sciences

$5-14-2009$

\title{
Luminescent Properties of Ensemble and Individual Erbium- Doped Yttrium Oxide Nanotubes
}

\author{
Yuanbing Mao \\ The University of Texas Rio Grande Valley, yuanbing.mao@utrgv.edu \\ Xia Guo \\ Thai Tran \\ Kang L. Wang \\ C. Ken Shih
}

See next page for additional authors

Follow this and additional works at: https://scholarworks.utrgv.edu/chem_fac

Part of the Chemistry Commons

\section{Recommended Citation}

Mao, Y., Guo, X., Tran, T., Wang, K. L., Shih, C. K., \& Chang, J. P. (2009). Luminescent properties of ensemble and individual erbium-doped yttrium oxide nanotubes. Journal of Applied Physics, 105(9), 094329. https://doi.org/10.1063/1.3117520

This Article is brought to you for free and open access by the College of Sciences at ScholarWorks @ UTRGV. It has been accepted for inclusion in Chemistry Faculty Publications and Presentations by an authorized administrator of ScholarWorks@ UTRGV.For more information, please contact justin.white@utrgv.edu,william.flores01@utrgv.edu. 
Authors

Yuanbing Mao, Xia Guo, Thai Tran, Kang L. Wang, C. Ken Shih, and Jane P. Chang

This article is available at ScholarWorks @ UTRGV: https://scholarworks.utrgv.edu/chem_fac/11 


\section{Luminescent properties of ensemble and individual erbium-doped yttrium oxide nanotubes}

Cite as: J. Appl. Phys. 105, 094329 (2009); https://doi.org/10.1063/1.3117520

Submitted: 03 October 2008 . Accepted: 17 March 2009 . Published Online: 14 May 2009

Yuanbing Mao, Xia Guo, Thai Tran, Kang L. Wang, C. Ken Shih, and Jane P. Chang

\section{ARTICLES YOU MAY BE INTERESTED IN}

Controlled erbium incorporation and photoluminescence of Er-doped $\mathrm{Y}_{2} \mathrm{O}_{3}$ Applied Physics Letters 87, 011907 (2005); https://doi.org/10.1063/1.1984082

High-pressure induced phase transitions of $\mathrm{Y}_{2} \mathrm{O}_{3}$ and $\mathrm{Y}_{2} \mathrm{O}_{3}$ : $\mathrm{Eu}^{3+}$

Applied Physics Letters 94, 061921 (2009); https://doi.org/10.1063/1.3082082

Spectral analysis of synthesized nanocrystalline aggregates of $\mathrm{Er}^{3+}: \mathrm{Y}_{2} \mathrm{O}_{3}$

Journal of Applied Physics 101, 113116 (2007); https://doi.org/10.1063/1.2739316

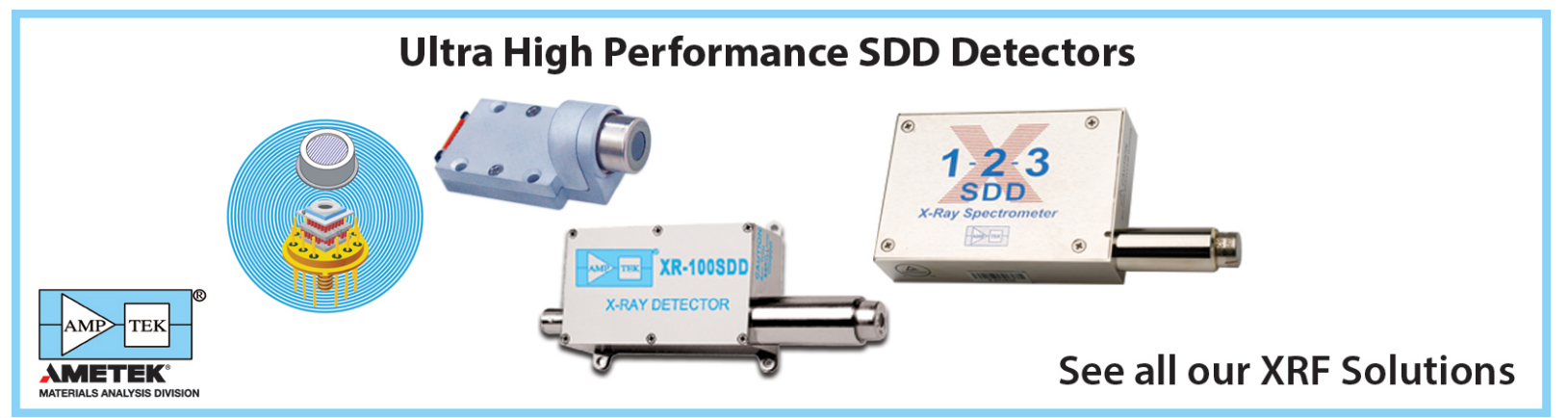

J. Appl. Phys. 105, 094329 (2009); https://doi.org/10.1063/1.3117520

(c) 2009 American Institute of Physics. 


\title{
Luminescent properties of ensemble and individual erbium-doped yttrium oxide nanotubes
}

\author{
Yuanbing Mao, ${ }^{1}$ Xia Guo, ${ }^{2}$ Thai Tran, ${ }^{3}$ Kang L. Wang, ${ }^{2}$ C. Ken Shih, ${ }^{3}$ and Jane P. Chang ${ }^{1, a)}$ \\ ${ }^{1}$ Department of Chemical and Biomolecular Engineering, UCLA, Los Angeles, California 90095, USA \\ ${ }^{2}$ Department of Electrical Engineering, UCLA, Los Angeles, California 90095, USA \\ ${ }^{3}$ Department of Physics, University of Texas, Austin, Texas 78712, USA
}

(Received 3 October 2008; accepted 17 March 2009; published online 14 May 2009)

\begin{abstract}
The luminescent properties, including cathodoluminescence and photoluminescence, of the erbium-doped yttrium oxide $\left(\mathrm{Er}^{3+}: \mathrm{Y}_{2} \mathrm{O}_{3}\right)$ nanotubes (NTs) have been systematically studied. These NTs were synthesized by a hydrothermal treatment followed by a dehydration process. Cathodoluminescent measurements show that every $\mathrm{Er}^{3+}: \mathrm{Y}_{2} \mathrm{O}_{3} \mathrm{NT}$ is luminescent under electron excitation. In the near-infrared region, sharp, well-resolved, pump-power-dependent, and thermally stable photoluminescence was observed from ensemble NTs. Individual NTs also present characteristic luminescent emissions in the same spectral region. These properties make these NTs promising for applications in display, bioanalysis, and telecommunication.
\end{abstract}

(C) 2009 American Institute of Physics. [DOI: 10.1063/1.3117520]

\section{INTRODUCTION}

Recently, nanosized luminescent materials have attracted intensive attention due to the high surface-to-volume ratio and the quantum confinement effect. The reduction in particle size in a crystalline system can result in remarkable modifications in some of their bulk properties. Therefore, nanosized luminescent materials, i.e., rare-earth (RE)-doped oxides and quantum dots, can exhibit novel physical properties, such as higher luminescent efficiency and better resolution of images in lighting and display. ${ }^{1-3}$ Moreover, REdoped oxides possess unique luminescent characteristics deriving from the RE dopants and are very stable in high vacuum. Hence, they have diverse potential applications in nanomaterial-based electronics, photonics, displays, and advanced bioanalyses. ${ }^{1,4-8}$ Because yttrium oxide $\left(\mathrm{Y}_{2} \mathrm{O}_{3}\right)$ has the same crystal structure and nearly the same lattice constants with most $\mathrm{RE}$ oxides $\left(\mathrm{RE}_{2} \mathrm{O}_{3}\right)$, it has received considerable attention as a host material for trivalent RE ions. This similarity in crystal structure allows the incorporation of high concentration of $\mathrm{RE}$ ions in $\mathrm{Y}_{2} \mathrm{O}_{3}$, compared to that in silicon dioxide. Particularly, numerous studies have been carried out on the $4 f^{11} \mathrm{Er}^{3+}$ ion, which exhibits the standard telecommunication wavelength emission at $1.54 \mu \mathrm{m} .{ }^{9}$

Most of the previous work on RE-doped oxide nanostructures focused on the materials synthesis, morphological and crystal structural characterization, and upconversion mechanism investigation of nanoparticles, nanorods, nanotubes (NTs), and nanowires. ${ }^{10-15}$ These nanostructures were synthesized by various procedures, such as the solutionbased sol-gel process, gel combustion synthesis, emulsion technique, coprecipitation process, hydrothermal process, template method, electrochemical process, or their combinations. ${ }^{16-32}$ For example, we have recently reported detailed studies on syntheses and morphological and crystal structural characterization of one dimensional (1D) erbium-

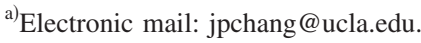

doped yttrium hydroxide $\left[\mathrm{Er}^{3+}: \mathrm{Y}(\mathrm{OH})_{3}\right]$ NTs and erbiumdoped yttrium oxide $\left(\mathrm{Er}^{3+}: \mathrm{Y}_{2} \mathrm{O}_{3}\right)$ NTs and the effect of local $\mathrm{Er}^{3+}$ dopant coordination environments on the photoluminescent spectral features of $\mathrm{Er}^{3+}: \mathrm{Y}_{2} \mathrm{O}_{3}$ NTs. ${ }^{32,33}$

Overall, the optical properties of individual nanosized luminescent emitters have received much attention, mainly on elemental, II-VI, and III-V semiconductors. ${ }^{34-38}$ These low-dimensional systems show interesting fundamental properties and have exciting prospects in nanotechnologyenabled optical and electronic applications. ${ }^{34-39}$ Although RE-doped oxides are important luminescent materials, very few reports investigated the luminescent properties from individual RE-doped oxide nanostructures. One such example is provided by Barnes et al. ${ }^{40}$ who studied on-off blinking and multiple bright states of single europium ions in $\mathrm{Eu}^{3+}: \mathrm{Y}_{2} \mathrm{O}_{3}$ nanocrystals $(5-15 \mathrm{~nm}$ in diameter). These effects have been attributed to the different quasistable $\mathrm{Eu}^{3+}$ symmetry sites that modulate the transition of electric dipole moment.

Since RE-doped oxide 1D nanostructures are important building blocks for future optical and optoelectronic nanodevices, it is evident that a thorough understanding of the optical behaviors of a promising material system, such as $\mathrm{Er}^{3+}: \mathrm{Y}_{2} \mathrm{O}_{3} \mathrm{NTs}$, can significantly advance the state-of-theart. Therefore, we report the luminescent properties of $\mathrm{Er}^{3+}: \mathrm{Y}_{2} \mathrm{O}_{3}$ NTs in this paper. We first present cathodoluminescent (CL) properties and pump-power-dependent and temperature-dependent photoluminescent behaviors in the near-infrared (NIR) region of ensemble powder samples. Also, photoluminescent behaviors in the NIR region from individual NTs are discussed.

\section{EXPERIMENT}

\section{A. Sample preparation}

The synthesis of $\mathrm{Er}^{3+}: \mathrm{Y}_{2} \mathrm{O}_{3}$ NTs is based on a previous report. ${ }^{32}$ First, $\mathrm{Y}\left(\mathrm{NO}_{3}\right)_{3}$ and $\mathrm{Er}\left(\mathrm{NO}_{3}\right)_{3}$ were dissolved in deionized $\mathrm{H}_{2} \mathrm{O}$, followed by the dropwise addition of $\mathrm{NaOH}$ 
solution under stirring. After being stirred for $1 \mathrm{~h}$, the solution was transferred into a Teflon-lined autoclave for hydrothermal treatment at $130{ }^{\circ} \mathrm{C}$ for $7 \mathrm{~h}$. After being cooled down to room temperature, the precipitate was washed with de-ionized $\mathrm{H}_{2} \mathrm{O}$. Finally, the obtained powder of $\mathrm{Er}^{3+}: \mathrm{Y}(\mathrm{OH})_{3}$ NTs was converted into the corresponding powder of $\mathrm{Er}^{3+}: \mathrm{Y}_{2} \mathrm{O}_{3}$ NTs by annealing at $500{ }^{\circ} \mathrm{C}$ for $3 \mathrm{~h}$ in a box furnace.

\section{B. Measurements}

In this work, we report optical properties of 5\% $\mathrm{Er}^{3+}: \mathrm{Y}_{2} \mathrm{O}_{3} \mathrm{NTs}$ to show the general trend. CL properties of $\mathrm{Er}^{3+}: \mathrm{Y}_{2} \mathrm{O}_{3}$ NTs were analyzed using a CL panchromatic imaging system and spectroscopy attached to a Hitachi S2250-N scanning electron microscope (SEM). Macrophotoluminescence (PL) measurements on ensemble $\mathrm{Er}^{3+}: \mathrm{Y}_{2} \mathrm{O}_{3}$ NTs and micro-PL measurements on individual $\mathrm{Er}^{3+}: \mathrm{Y}_{2} \mathrm{O}_{3} \mathrm{NTs}$ were performed with a $488 \mathrm{~nm}$ argon ion laser and a $532 \mathrm{~nm}$ frequency doubled diode pumped Nd:yttrium aluminum garnet laser, respectively, both operated with liquid nitrogen cooled InGaAs detectors. For micro-PL measurements, due to the stage and image drift during heating and cooling of the sample stage, it was not possible to track an individual NT and take the measurements at two very different temperatures. While every effort was made to locate a single NT once the stage reached a given temperature, it was not always possible. In this work, an individual NT refers to a single NT or a single NT seemingly clumped/ overlapped with no more than one or two much smaller/ shorter NTs. To prepare samples for SEM, CL, and PL measurements, powders of $\mathrm{Er}^{3+}: \mathrm{Y}_{2} \mathrm{O}_{3}$ NTs were added into ethanol, and the mixtures were subsequently sonicated for about $1 \mathrm{~min}$ and later air-dried upon deposition onto silicon wafers.

\section{RESULTS AND DISCUSSION}

\section{A. SEM and X-ray Diffraction (XRD)}

Figure 1(a) shows a typical SEM image of $\mathrm{Er}^{3+}: \mathrm{Y}_{2} \mathrm{O}_{3}$ NTs with 5\% doping level. The as-prepared NTs are measured to be a few micrometers long and $100-400 \mathrm{~nm}$ in outer diameter. As previously reported, the basic 1D topological morphology of the initial $\mathrm{Er}^{3+}: \mathrm{Y}(\mathrm{OH})_{3} \mathrm{NTs}$ was found to be preserved after a moderate high-temperature annealing process to form $\mathrm{Er}^{3+}: \mathrm{Y}_{2} \mathrm{O}_{3}$ NTs. ${ }^{32}$ This observation suggests that the initial $\mathrm{Er}^{3+}: \mathrm{Y}(\mathrm{OH})_{3}$ structural motifs are not affected by the subsequent thermal treatment. In addition, powder and synchrotron XRD analyses confirmed that these 5\% $\mathrm{Er}^{3+}: \mathrm{Y}_{2} \mathrm{O}_{3}$ NTs are of a cubic bixbyite $\mathrm{Y}_{2} \mathrm{O}_{3}$ structure (space group: Ia3), ${ }^{41}$ without observable impurities (data not shown here). ${ }^{32,33}$

\section{B. $\mathrm{CL}$}

By comparing the simultaneously recorded SEM and CL panchromatic images, as shown in Figs. 1(a) and 1(b), it is clear that every $\mathrm{Er}^{3+}: \mathrm{Y}_{2} \mathrm{O}_{3} \mathrm{NT}$ is luminescent under electron excitation, thereby achieving the observed spatial distribution of luminescence. The CL voltage from these $5 \%$
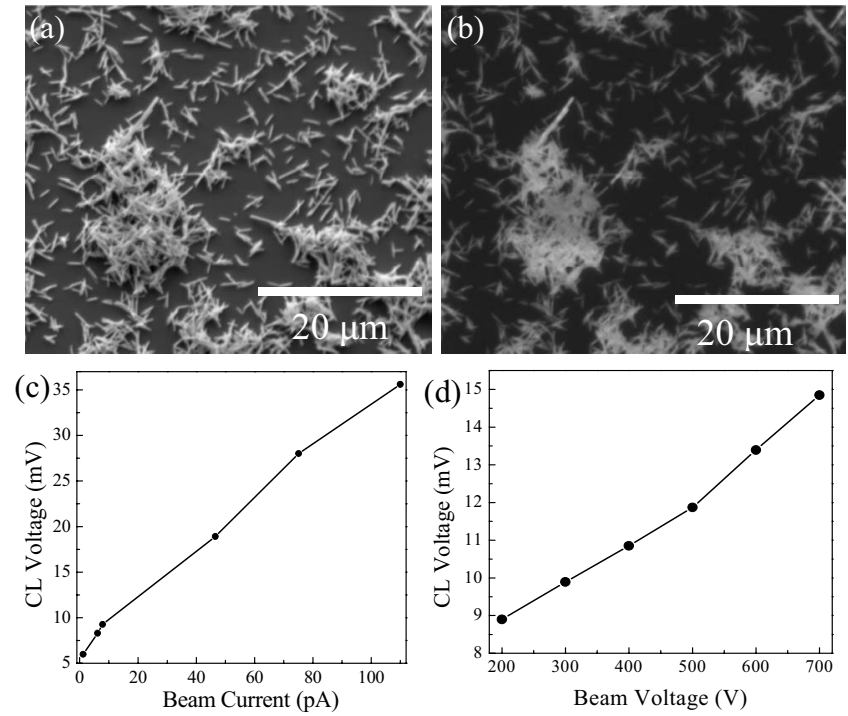

FIG. 1. CL characterization of $5 \% \mathrm{Er}^{3+}: \mathrm{Y}_{2} \mathrm{O}_{3}$ NTs. (a) SEM image and (b) $\mathrm{CL}$ panchromatic image recorded simultaneously under $7 \mathrm{kV}$ accelerating voltage. (c) and (d) are the CL voltage as a function of beam current with a fixed beam voltage of $700 \mathrm{~V}$ and that as a function of applied voltage with a fixed beam current of $30 \mathrm{pA}$, respectively.

$\mathrm{Er}^{3+}: \mathrm{Y}_{2} \mathrm{O}_{3}$ NTs gradually increases but does not saturate with increasing electron beam current up to $110 \mathrm{pA}$ under a fixed beam voltage of $700 \mathrm{~V}$ [Fig. 1(c)]. The CL voltage increases with increasing acceleration voltages from 200 to $700 \mathrm{~V}$ at a fixed beam current of $30 \mathrm{pA}$ [Fig. 1(d)]. Good CL properties are important for developing successful phosphors for field emission display (FED) applications. The excellent CL properties presented here suggest that these $\mathrm{Er}^{3+}: \mathrm{Y}_{2} \mathrm{O}_{3}$ NTs are promising luminescent materials for FEDs.

\section{PL of ensemble NTs}

PL measurements were performed with a $488 \mathrm{~nm}$ laser at room temperature on 5\% $\mathrm{Er}^{3+}: \mathrm{Y}_{2} \mathrm{O}_{3}$ NTs. As shown in Figs. 2(a) and 2(b), these $\mathrm{Er}^{3+}: \mathrm{Y}_{2} \mathrm{O}_{3}$ NTs exhibit remarkably sharp and well-resolved peaks at around 870, 980, and $1535 \mathrm{~nm}$, which correspond to the characteristic ${ }^{4} S_{3 / 2} \rightarrow{ }^{4} I_{13 / 2},{ }^{4} I_{11 / 2}$ $\rightarrow{ }^{4} I_{15 / 2}$, and ${ }^{4} I_{13 / 2} \rightarrow{ }^{4} I_{15 / 2}$ transitions of $\mathrm{Er}^{3+}$ ions, respectively. It indicates that $\mathrm{Er}^{3+}$ ions occupy well-defined locations in the $\mathrm{Y}_{2} \mathrm{O}_{3}$ lattice, i.e., replace the $\mathrm{Y}^{3+}$ ions. If $\mathrm{Er}^{3+}$ ions have an aperiodic distribution in different crystallographic sites (i.e., interstitial sites), it would randomize the
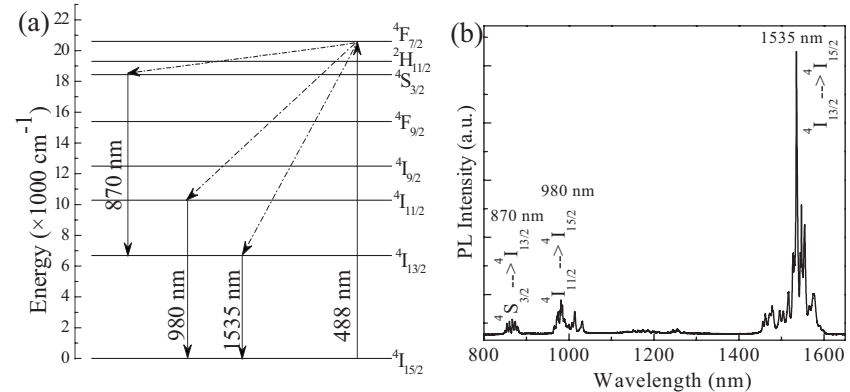

FIG. 2. PL of $5 \%$ doped $\mathrm{Er}^{3+}: \mathrm{Y}_{2} \mathrm{O}_{3}$ NTs excited at $488 \mathrm{~nm}$ at room temperature. (a) An energy level diagram of free $\mathrm{Er}^{3+}$ ions. (b) A typical spectrum in the wavelength range of 800 to $1640 \mathrm{~nm}$. 

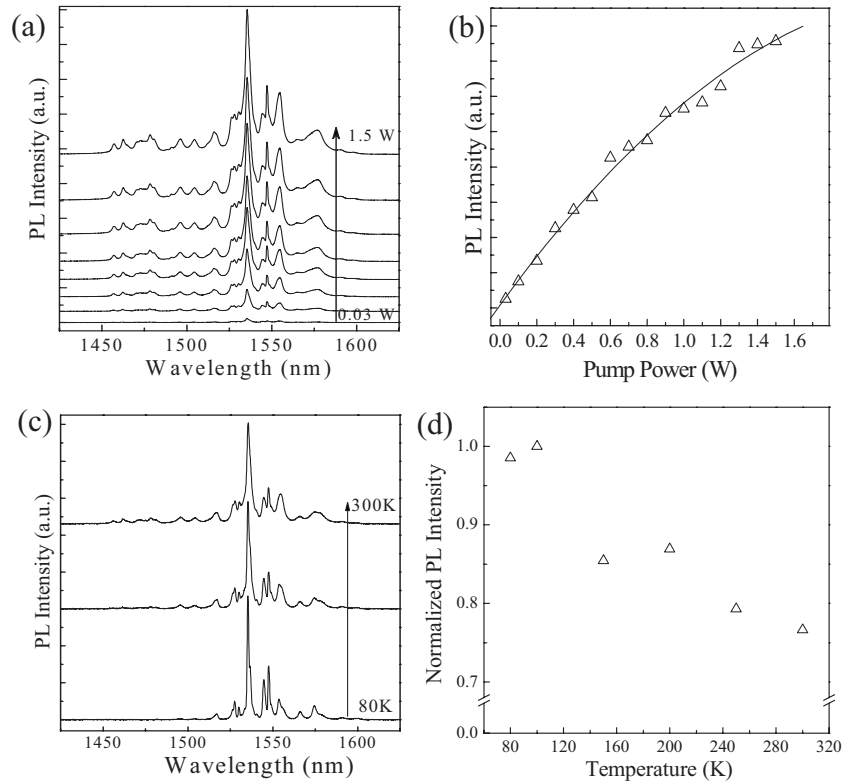

FIG. 3. [(a)-(b)] Pump-power-dependence of 5\% doped $\mathrm{Er}^{3+}: \mathrm{Y}_{2} \mathrm{O}_{3}$ NTs excited at $488 \mathrm{~nm}$ at room temperature. (a) Selected PL spectra (offset for clarification) pumped at various powers from $30 \mathrm{~mW}$ to $1.5 \mathrm{~W}$. (b) Integrated PL yield ( $\triangle$ symbols) in the wavelength range of $1420-1630 \mathrm{~nm}$ as a function of pump power. [(c)-(d)] Temperature-dependence of 5\% doped $\mathrm{Er}^{3+}: \mathrm{Y}_{2} \mathrm{O}_{3}$ NTs excited at $488 \mathrm{~nm}$. (c) Selected PL spectra (offset for clarification) pumped at various temperatures from 80 to $300 \mathrm{~K}$ collected at a constant pump power of $0.5 \mathrm{~W}$ and a $10 \mathrm{~s}$ dwell time. (d) Normalized integrated PL yield ( $\triangle$ symbols) in the wavelength range of $1420-1630 \mathrm{~nm}$ as a function of measurement temperature. The solid line in (b) is used for visual guiding purpose only.

Stark splitting and result in a homogeneous spectral broadening. ${ }^{42}$ These results also indicate that no annealing at temperatures higher than $500{ }^{\circ} \mathrm{C}$ is needed to optically activate the erbium ions in these $\mathrm{Er}^{3+}: \mathrm{Y}_{2} \mathrm{O}_{3}$ NTs.

In addition, the integrated intensities between 1420 and $1630 \mathrm{~nm}$ from PL spectra taken under laser pump powers from $30 \mathrm{~mW}$ to $1.5 \mathrm{~W}$ [Fig. 3(a)] are plotted in Fig. 3(b) for these $\mathrm{Er}^{3+}: \mathrm{Y}_{2} \mathrm{O}_{3}$ NTs. The PL intensity increases with the increasing excitation power, but the peaks exhibit no shift [Fig. 3(a)]. The increase in PL intensity is almost linear as the pump power increases up to about $1.0 \mathrm{~W}$ [Fig. 3(b)]. As the pump power increases above $1.0 \mathrm{~W}$, the PL intensity starts to saturate, which represents the onset of a complete excitation. Another notable feature is that a sufficient fraction of $\mathrm{Er}^{3+}$ ions are excitable at a pump power as low as $30 \mathrm{~mW}$, as seen from the measurable PL intensity.

We also investigated the temperature-dependent PL quenching of $\mathrm{Er}^{3+}: \mathrm{Y}_{2} \mathrm{O}_{3}$ NTs from 80 to $300 \mathrm{~K}$ [Figs. 3(c) and $3(\mathrm{~d})$ ]. It was reported that the thermal quenching is a major limiting factor for achieving high room-temperature PL yield in Er-doped Si-based materials, ${ }^{43-45}$ with a reduction in PL intensity by at least two orders of magnitude from 200 to $300 \mathrm{~K}$. Our $\mathrm{Er}^{3+}: \mathrm{Y}_{2} \mathrm{O}_{3}$ NTs show relatively constant $\mathrm{PL}$ intensity with the characteristic $\mathrm{Er}^{3+}$ intra- $4 f$ transition from 80 to $300 \mathrm{~K}$ [Fig. 3(c)]. This lack of thermal quenching is similar to that observed in 50-90 nm Er ${ }^{3+}: \mathrm{Y}_{2} \mathrm{O}_{3}$ thin films synthesized by a low temperature radical-enhanced atomic layer deposition process. ${ }^{5}$ This is attributed to the large band gap of $\mathrm{Y}_{2} \mathrm{O}_{3}(\sim 5.6 \mathrm{eV})$, which inhibits Auger quenching

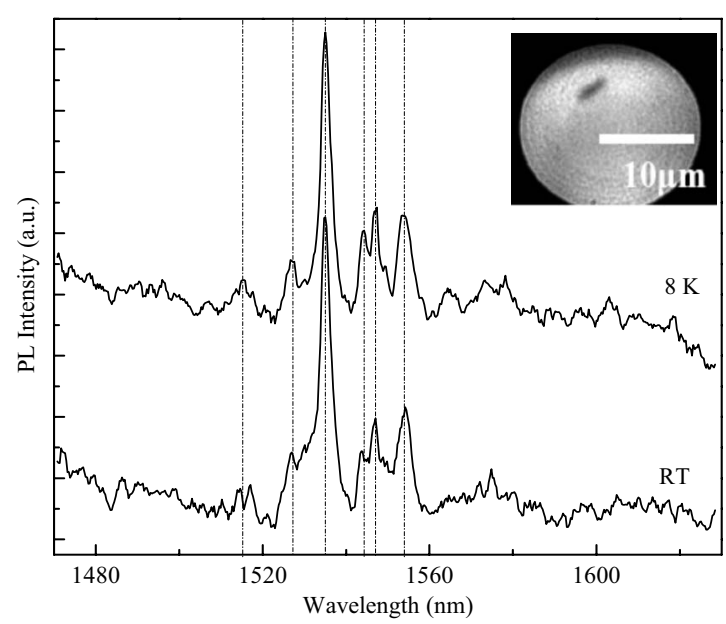

FIG. 4. PL studies of individual $5 \% \mathrm{Er}^{3+}: \mathrm{Y}_{2} \mathrm{O}_{3}$ NTs excited at $532 \mathrm{~nm}$. PL spectra taken at $8 \mathrm{~K}$ and room temperature in the wavelength range of $1470-1630 \mathrm{~nm}$. The inset is the corresponding optical microscopic image of the individual NT for taking the PL spectrum at $8 \mathrm{~K}$.

and energy back-transfer processes, which are found to dominate in Si-based materials. ${ }^{46}$ Also, these $\mathrm{Er}^{3+}: \mathrm{Y}_{2} \mathrm{O}_{3}$ NTs do not show any broad luminescent background band, which is characteristic for defect-mediated radiative transitions. ${ }^{43-45}$

\section{PL of individual NTs}

The PL properties of individual $\mathrm{Er}^{3+}: \mathrm{Y}_{2} \mathrm{O}_{3}$ NTs were investigated by using a $532 \mathrm{~nm}$ laser source, while the corresponding morphological images were simultaneously acquired using an optical microscope. Figure 4 shows the characteristic ${ }^{4} I_{13 / 2} \rightarrow{ }^{4} I_{15 / 2}$ transitions of $\mathrm{Er}^{3+}$ ions in individual $\mathrm{Er}^{3+}: \mathrm{Y}_{2} \mathrm{O}_{3} \mathrm{NTs}$ at $8 \mathrm{~K}$ and room temperature, respectively. The inset of Fig. 4 is a microscopic image of an individual NT, corresponding to the spectrum taken at $8 \mathrm{~K}$. Qualitatively, the spectral line shape and details observed in these individual NTs are very similar to those observed in ensemble NTs by the macro-PL method [Fig. 2(d) versus Fig. 4]. More importantly, individual $\mathrm{Er}^{3+}: \mathrm{Y}_{2} \mathrm{O}_{3}$ NTs do not show broad luminescence background bands. These results again validate our previous conclusion that erbium ions occupy well-defined location in the $\mathrm{Y}_{2} \mathrm{O}_{3}$ lattice, further supported by synchrotron-based XRD, X-ray absorption near-edge spectroscopy, and extended x-ray absorption fine structure studies of $\mathrm{Er}^{3+}: \mathrm{Y}_{2} \mathrm{O}_{3}$ NT powder samples. ${ }^{32,33}$ Therefore, each of these $\mathrm{Er}^{3+}: \mathrm{Y}_{2} \mathrm{O}_{3}$ NTs is a promising luminescent emitter for nanotechnology-enabled optical and electronic applications. Since RE-doped oxide nanostructures have unique and stable luminescent characteristics depending on the specific RE dopants, they are promising alternatives to semiconductor quantum dots. ${ }^{34-39}$ This study on individual $\mathrm{Er}^{3+}: \mathrm{Y}_{2} \mathrm{O}_{3}$ NTs thus serves a dual purpose: it sets the stage for a more profound study on optoelectronic properties of individual $\mathrm{Er}^{3+}: \mathrm{Y}_{2} \mathrm{O}_{3} \mathrm{NTs}$ and paves the way for a similar study on more complex RE-doped oxide nanostructures, e.g., (Er, Yb): $\mathrm{Gd}_{2} \mathrm{O}_{3}$ nanowires, ${ }^{10} \mathrm{Eu}: \mathrm{Gd}_{2} \mathrm{O}_{3}$ nano/microrods, ${ }^{14}$ and $\mathrm{Eu}: \mathrm{GdVO}_{4}$ nanorods. ${ }^{12}$ 


\section{CONCLUSIONS}

In summary, the luminescent properties, including cathodoluminescence and both pump-power- and temperaturedependent PL, of ensemble and individual $\mathrm{Er}^{3+}: \mathrm{Y}_{2} \mathrm{O}_{3}$ NTs have been systematically studied. The $\mathrm{CL}$ measurements show that each $\mathrm{Er}^{3+}: \mathrm{Y}_{2} \mathrm{O}_{3} \mathrm{NT}$ is CL. The luminescent under electron excitation voltage from ensemble NTs gradually increases with both increasing beam current and the increase in the acceleration voltage. These $\mathrm{Er}^{3+}: \mathrm{Y}_{2} \mathrm{O}_{3}$ NTs are also highly photoluminescent with remarkably sharp and wellresolved peaks at around 870, 980, and $1535 \mathrm{~nm}$. These NTs show strong pump-power-dependence and, measurable PL intensities with pump power of as low as $30 \mathrm{~mW}$ and minor temperature-dependence. Individual NTs also present characteristic luminescent emissions in the NIR region. These results indicate that these materials are promising for applications in display, bioanalysis, and telecommunication.

\section{ACKNOWLEDGMENTS}

The authors acknowledge the financial and program support from National Science Foundation (Grant No. CTS0522534), the Office of Naval Research (a Young Investigator Award), the Semiconductor Research Corporation (SRC) and its Focus Center Research Program (FCRP).

${ }^{1}$ F. Vetrone, J.-C. Boyer, and J. A. Capobianco, in Encyclopedia of Nanoscience and Nanotechnology, edited by H. S. Nalwa (American Scientific Publishers, Stevenson Ranch, CA, 2004), Vol. 10, p. 725.

${ }^{2}$ Y. L. Soo, S. W. Huang, Y. H. Kao, V. Chhabra, B. Kulkarni, J. V. D. Veliadis, and R. N. Bhargava, Appl. Phys. Lett. 75, 2464 (1999).

${ }^{3}$ A. Konrad, U. Herr, R. Tidecks, F. Kummer, and K. Samwer, J. Appl. Phys. 90, 3516 (2001).

${ }^{4}$ A. J. Steckl and J. M. Zavada, MRS Bull. 24, 16 (1999) (and references therein).

${ }^{5}$ T. T. Van, J. Hoang, R. Ostroumov, K. L. Wang, J. R. Bargar, J. Lu, H.-O. Blom, and J. P. Chang, J. Appl. Phys. 100, 073512 (2006).

${ }^{6}$ T. Minami, Solid-State Electron. 47, 2237 (2003).

${ }^{7}$ J. Yan, M. C. Estevez, J. E. Smith, K. Wang, X. He, L. Wang, and W. Tan, Nanotoday 2, 44 (2007).

${ }^{8}$ M. H. Lee, S. G. Oh, S. C. Yi, D. S. Seo, J. P. Hong, C. O. Kim, Y. K. Yoo, and J. S. Yoo, J. Electrochem. Soc. 147, 3139 (2000).

${ }^{9}$ A. J. Kenyon, Prog. Quantum Electron. 26, 225 (2002).

${ }^{10}$ Y. Lei, H. Song, L. Yang, L. Yu, Z. Liu, G. Pan, X. Bai, and L. Fan, J. Chem. Phys. 123, 174710 (2005).

${ }^{11} \mathrm{X}$. Li, Q. Li, J. Wang, and J. Li, J. Lumin. 124, 351 (2007).

${ }^{12}$ M. Gu, Q. Liu, S. Mao, D. Mao, and C. Chang, Cryst. Growth Des. 8, $1422(2008)$.

${ }^{13}$ X. Bai, H. Song, L. Yu, L. Yang, Z. Liu, G. Pan, S. Lu, X. Ren, Y. Lei, and L. Fan, J. Phys. Chem. B 109, 15236 (2005).
${ }^{14}$ J. Yang, C. Li, Z. Cheng, X. Zhang, Z. Quan, C. Zhang, and J. Lin, J. Phys. Chem. C 111, 18148 (2007).

${ }^{15}$ X. Bai, H. Song, G. Pan, Y. Lei, T. Wang, X. Ren, S. Lu, B. Dong, Q. Dai, and L. Fan, J. Phys. Chem. C 111, 13611 (2007).

${ }^{16}$ J. Zhang, S. Wang, T. Rong, and L. Chen, J. Am. Ceram. Soc. 87, 1072 (2004).

${ }^{17}$ J. A. Capobianco, F. Vetrone, J. C. Boyer, A. Speghini, and M. Bettinelli, J. Phys. Chem. B 106, 1181 (2002).

${ }^{18}$ H. Eilers, Mater. Lett. 60, 214 (2006).

${ }^{19} \mathrm{G}$. De, W. Qin, J. Zhang, Y. Wang, C. Cao, and Y. Cui, J. Lumin. 119-120, 258 (2006).

${ }^{20} \mathrm{X}$. Wang and Y. Li, Chem.-Eur. J. 9, 5627 (2003).

${ }^{21}$ L. Yang, Y. Tang, X. Chen, Y. Li, and X. Cao, Mater. Chem. Phys. 101, 195 (2007)

${ }^{22}$ G. S. Wu, Y. Lin, X. Y. Yuan, T. Xie, B. C. Cheng, and L. D. Zhang, Nanotechnology 15, 568 (2004).

${ }^{23}$ Y.-P. Fang, A.-W. Xu, L.-P. You, R.-Q. Song, J. C. Yu, H.-X. Zhang, Q. Li, and H.-Q. Liu, Adv. Funct. Mater. 13, 955 (2003).

${ }^{24}$ A. M. Pires, O. A. Serra, S. Heer, and H. U. Gudel, J. Appl. Phys. 98, 063529 (2005)

${ }^{25}$ J. A. Capobianco, F. Vetrone, T. D’Alesio, G. Tessari, A. Speghini, and M. Bettinelli, Phys. Chem. Chem. Phys. 2, 3203 (2000).

${ }^{26}$ Z. Xu, Z. Hong, Q. Zhao, L. Peng, and P. Zhang, J. Rare Earths 24, 111 (2006).

${ }^{27}$ Q. Tang, Z. Liu, S. Li, S. Zhang, X. Liu, and Y. Qian, J. Cryst. Growth 259, 208 (2003).

${ }^{28}$ V. V. Rajasekharan and D. A. Buttry, Chem. Mater. 18, 4541 (2006).

${ }^{29}$ T. Hirai, T. Orikoshi, and I. Komasawa, Chem. Mater. 14, 3576 (2002).

${ }^{30}$ J. Silver, M. I. Martinez-Rubio, T. G. Ireland, G. R. Fern, and R. Withnall, J. Phys. Chem. B 105, 948 (2001).

${ }^{31}$ W. O. Gordon, B. M. Tissue, and J. R. Morris, J. Phys. Chem. C 111, 3233 (2007).

${ }^{32}$ Y. Mao, J. Huang, R. Ostroumov, K. L. Wang, and J. P. Chang, J. Phys. Chem. C 112, 2278 (2008).

${ }^{33}$ Y. Mao, J. Bargar, M. Toney, and J. P. Chang, J. Appl. Phys. 103, 094316 (2008).

${ }^{34}$ J. Qi, A. M. Belcher, and J. M. White, Appl. Phys. Lett. 82, 2616 (2003).

${ }^{35}$ D. Kulik, H. Htoon, C. K. Shih, and Y. Li, J. Appl. Phys. 95, 1056 (2004).

${ }^{36}$ J. Wang, M. S. Gudiksen, X. Duan, Y. Cui, and C. M. Lieber, Science 293, 1455 (2001)

${ }^{37}$ J. A. Zapien, Y. Jiang, X. M. Meng, W. Chen, F. C. K. Au, Y. Lifshitz, and S. T. Lee, Appl. Phys. Lett. 84, 1189 (2004).

${ }^{38}$ C. X. Shan, Z. Liu, and S. K. Hark, Phys. Rev. B 74, 153402 (2006).

${ }^{39}$ T. Yatsui, M. Ohtsu, S. J. An, J. Yoo, and G.-C. Yi, Opt. Rev. 13, 218 (2006).

${ }^{40}$ M. D. Barnes, A. Mehta, T. Thundat, R. N. Bhargava, V. Chhabra, and B. Kulkarni, J. Phys. Chem. B 104, 6099 (2000).

${ }^{41}$ JCPDS Card No. 41-1105.

${ }^{42}$ T. T. Van and J. P. Chang, Appl. Phys. Lett. 87, 011907 (2005).

${ }^{43}$ S. Fukatsu, Y. Mera, M. Inoue, K. Maeda, H. Akiyama, and H. Sakaki, Appl. Phys. Lett. 68, 1889 (1996).

${ }^{44}$ V. V. Kveder, E. A. Steinman, S. A. Shevchenko, and H. G. Grimmeiss, Phys. Rev. B 51, 10520 (1995).

${ }^{45}$ R. Sauer, C. Kisielowski-Kemmerich, and H. Alexander, Phys. Rev. Lett. 57, 1472 (1986).

${ }^{46}$ A. J. Kenyon, Curr. Opin. Solid State Mater. Sci. 7, 143 (2003). 